\title{
Response to: Management of Traumatic Spinal Fracture in the Coronavirus Disease 2019 Situation
}

\author{
Wongthawat Liawrungrueang ${ }^{1}$, Tuanrit Sornsa-ard ${ }^{2}$, Anugoon Niramitsantiphong ${ }^{2}$ \\ ${ }^{1}$ Department of Orthopedics, Faculty of Medicine, Prince of Songkla University, Songkhla, Thailand \\ ${ }^{2}$ Department of Orthopedics, Nakornping Hospital, Chiang Mai, Thailand
}

Dear Sir,

We appreciate the letter regarding our manuscript titled "Management of traumatic spinal fracture in the coronavirus disease 2019 situation [1]." We thank the reader(s) for reading our article. Our reply to the comment is as follows:

Our reply: First of all, the authors wish to thank Dobran Mauro, Mancini Fabrizio, and Iacoangeli Maurizio for sharing the experience of the neurosurgical team working in the Emergency Regional Hospital of Ancona (Italy). In our review article [1], all authors intend to establish the prototype to help and protect the health care professionals. This algorithm must be revised or modified according to the updated knowledge of prevention, novel treatment, and laboratory testing technology for coronavirus disease 2019 (COVID-19). All the authors hope that the readers would use this algorithm as a prototype and modify/develop for a better protocol.

All authors agree with Dobran Mauro, Mancini Fabrizio, and Iacoangeli Maurizio that early surgery $(<12$ hours) is the best choice for patients with spinal cord injury [2]; however, currently, they believe that surgery within 24 hours may be a reasonable target because we need to obtain the swab test result before starting surgery for all patients. All authors recommend that universal precautions should be taken in the surgical management of any patient during the COVID-19 outbreak crisis [3,4].

Thank you for your selfless patience to dedicate the efforts and intention to make the project go as planned, even though it is extremely difficult.

\section{Conflict of Interest}

No potential conflict of interest relevant to this article was reported.

\section{Acknowledgments}

Thank you to the Institutional Ethics Review Board at Nakornping Hospital.

\section{ORCID}

Wongthawat Liawrungrueang: https://orcid.org/00000002-4491-6569; Tuanrit Sornsa-ard: https://orcid. org/0000-0003-4021-1278

Received May 6, 2020; Accepted May 6, 2020

Corresponding author: Wongthawat Liawrungrueang

Department of Orthopedics, Faculty of Medicine, Prince of Songkla University, Hat Yai, Songkhla 90110, Thailand

Tel: +66-891483458, Fax: +66-74451603, E-mail: mint11871@hotmail.com 


\section{References}

1. Sornsa-Ard T, Niramitsantiphong A, Liawrungrueang W. Management of traumatic spinal fracture in the coronavirus disease 2019 situation. Asian Spine J 2020 Apr 24 [Epub]. https://doi.org/10.31616/ asj.2019.0183.

2. Nasi D, Ruscelli P, Gladi M, Mancini F, Iacoangeli M, Dobran M. Ultra-early surgery in complete cervical spinal cord injury improves neurological recovery: a single-center retrospective study. Surg Neurol Int 2019;10:207.

3. Centers for Disease Control and Prevention. What healthcare personnel should know about caring for patients with confirmed or possible COVID-19 infection [Internet]. Atlanta (GA): Centers for Disease Control and Prevention; 2020 [cited 2020 Mar 6]. Available from: http://www.cdc.gov/ coronavirus/2019-ncov/hcp/caring-for-patients. html.

4. Centers for Disease Control and Prevention. Strategies for optimizing the supply of N95 respirators [Internet]. Atlanta (GA): Centers for Disease Control and Prevention; 2020 [cited 2020 Apr 26]. Available from: https://www.cdc.gov/coronavirus/2019-ncov/ hcp/respirators-strategy/index.html. 